\title{
Animal Organ Dissections in High Schools: Is There More than just Cutting?
}

\author{
Portia Kavai, Rian de Villiers*, William Fraser, Jaqui Sommerville and Nina Strydom \\ University of Pretoria, Pretoria, South Africa \\ ${ }^{*}$ Corresponding author. Faculty of Education, University of Pretoria, Pretoria, 0002, South Africa. \\ Email: rian.devilliers@up.ac.za
}

\begin{abstract}
In Life Sciences education internationally, including South Africa, the study of animal and organ morphology has traditionally involved dissections since the early nineteenth century. The major purpose of this study was to investigate how the engagement of learners with animal organ dissections may influence the development of problem-solving skills and how teachers use animal dissections to develop these skills of Grade 11 learners in Life Sciences (Biology) education. A mixed-methods research design was used for this study. Data were collected from a pre-test and a post-test (which had predominantly problem-solving questions), a learner questionnaire, lesson observations and teacher interviews. Tests and questionnaires were administered to 224 Grade 11 Life Sciences learners. Six Grade 11 Life Sciences teachers at four high schools from different environments participated in the study. The pre-test and post-test scores were compared using a parametric matched $t$-test. The comparison for the five cognitive levels including rote learning and problem-solving as well as the total calculation were all highly significant with $p$-values $<0.0001$. The learners' responses in the questionnaire and the teachers' responses during the interviews indicate their acknowledgement that animal organ dissection may be used to develop problem-solving skills. The results show that there is more to animal organ dissection than just cutting and drawing; it may be used as a problem-solving teaching strategy. The level of learner engagement with animal organ dissections can determine the level of development of problem-solving skills. This study recommends that teachers should be encouraged to link animal organ dissections to specific anatomical and physiological problems where applicable, and to allow learners to solve these problems when performing the dissections; they should not merely let the learners cut, draw and label the organ.
\end{abstract}

Keywords: Animal organ dissections; Biology; Life Sciences; problem-solving teaching strategy; problem-solving skills

\section{Introduction}

Life Sciences (previously known as Biology within the South African context) is one of the school subjects taught in Grades 10-12, which are the final 3 years of high school in South Africa. The South African Department of Education (2003) stated in the Life Sciences National Curriculum Statement the need to include dissection as part of the study of organ anatomy in Grades 10-12. The interest in the use of dissection in the acquisition of problem-solving skills in Life Sciences emanated from the researcher's experiences as a Grade 11 Life Sciences teacher, where it is a requirement for learners to carry out animal organ dissections of hearts, kidneys and lungs as part of the curriculum.

Problem-solving skills enable the learner to solve problem-based questions related to the organs dissected to then apply the skill in other circumstances. However, this can only be possible if the teacher emphasises the steps the learner can follow to solve questions related to the dissected organ. These 
may include the APIE (Assess Plan Implement and Evaluate) problem-solving model suggested by Beekman (2000) which includes:

- assessing the problem, gathering information about the problem;

- planning to solve the problem, working out a plan of action;

- implementing the action plan, recording actions and responses;

- evaluating the effectiveness of the action plan or whether the problem has been solved.

In some cases problem solving may not be as good as it could be because the real problem has not been identified: one ends up finding a solution to the wrong problem, resulting in failure to solve the actual problem. The APIE model incorporates rational, creative and critical thinking skills.

The question that comes to mind is: "What is the use of carrying out animal organ dissections in high schools where learners just cut and draw: isn't there more to dissection than just cutting and drawing?' Through teaching experience, it was observed that learners seemed to be more interested in dissection when they cut through the organs and observed the connection between structure and function, and when they were presented with challenging questions related to day-to-day health problems linked to these organs. This observation agrees with work done by other researchers, including Holstermann, Grube and Bögeholz (2010), and Preszler, Dawe, Shuster and Shuster (2007). These observations suggest that it would make more sense to use dissections of animal organs as a way to help learners acquire problem-solving skills. This would also help them realise the relevance of studying Life Sciences at school. Animal or organ dissections are still widely used irrespective of their controversy in pedagogical practice and social pressure (Oakley, 2012) owing to ethical and environmental concerns regarding killing the animals. This has prompted debates on the use of alternatives to dissection such as real or virtual anatomical models in North America, Canada, Australia, UK and other parts of the world, including South Africa (De Villiers \& Monk, 2005; Franklin, Peat \& Lewis, 2002; Hart, Wood \& Hart, 2008). However, irrespective of the controversy, it is argued that methods that promote meaningful learning, such as problem-solving and learning by discovery, include dissections, identifying parts of organs and critical thinking (Handelsman, 2004; National Science Teachers Association, 2005). This study is therefore meant to apply the notion of using dissections in problem-solving as a teaching strategy in Life Sciences education.

Many educational philosophers and academics internationally and nationally (Capps, Constas \& Crawford, 2012; The National Research Council, 2000; Roehrig, Dubinsky, MacNabb, Michlin \& Schmitt, 2012) have advocated for enquiry to be part of Life Sciences education. They assert that enquiry-based approaches to teaching and learning provide a framework for learners for the acquisition of critical thinking and problem-solving skills. Many authors, including McCain (2005), Oakley (2012), Offner (1993) and Preszler et al. (2007), have advocated the importance of animal dissections in the teaching of Biology (Life Sciences). They concur that dissection, as practical work, may be used by Life Sciences teachers as a means to break the monotony of class work. Dissection, as a method of enquiry, plays an important role in the teaching and learning of Life Sciences but, unfortunately, very few teachers are using enquiry-based instruction in actually building problem-solving activities and skills into their dissection lessons (Capps et al., 2012; Smith, Banilower, McMahon \& Weiss, 2002). Even though dissections are widely carried out internationally and nationally, there seems to be a dearth of literature on the use of animal organ dissections to develop problem-solving skills.

It is vitally important when dealing with dissections to consider how learners at different levels of education feel about doing dissections. A few authors, including Hart et al. (2008) and Nabi (2002), have established that some learners find the dissection task disgusting and become anxious to dissect properly. Randler, Wust-Ackermann, Vollmer and Hummel (2012) also established that emotions, such as anxiety and disgust, had a negative influence on motivation. This was proved by students with more experience in dissections being reported to be less anxious. This basically indicated that, the more learners are exposed to dissections, the less disgusted and anxious they become and in time they enjoy the dissections. However, Nabi (2002) argues that for some learners it is both unpleasant and very intriguing, and if the intrigue is stronger than the unpleasantness, then the disgust plays a role in making the experience much more memorable, and it is the role of the teachers to motivate the learners towards the dissection, emphasizing its importance in developing skills like problem solving. 


\section{Conceptual Framework}

Based on the literature review, the concepts relevant to this study were summarised as the overall conceptual framework of the study. It includes how learners, through a scientific enquiry using hands-on activities, may generate their own knowledge. Through these activities the learners can acquire basic and advanced scientific process and cognitive skills (Millar, 2004). This overall conceptual framework could be related to the particular skills to be developed through animal organ dissections. The role of the scientific enquiry according to the literature is to enable learners to acquire basic and advanced scientific process skills by carrying out hands-on activities (Bennett \& Lubben, 2006), like animal organ dissections. Learners discuss their observations in groups and capture the data, which will help them to answer ill-structured problem-solving questions. During the discussions an intense rationalisation is involved as the learners engage with the dissections of animal organs and debate until they agree as a group on the emerging meaning. The challenges presented by the questions motivate the learners to explore and engage with the organ, seeking the answers that they can get from observing the organs. The knowledge generated results in cognitive learning and the development of problemsolving skills as the learners strive to solve the given questions.

\section{Research Questions}

The following research questions guided the investigation:

- How do learners' engagements with animal organ dissections influence the development of problem-solving skills?

- How do teachers use animal dissections to develop problem-solving skills of Grade 11 learners?

\section{Research Methodology}

\section{Research Design}

This study adopted a mixed-method approach, and more specifically, the concurrent embedded strategy (Creswell, 2009). This is a combination of concurrent quantitative and qualitative research methods that can be used deductively and inductively when presenting data numerically and in an explanatory manner (Creswell \& Plano Clark, 2011). The reason for using the mixed-method approach was to ensure that both approaches complemented one another, and also for the purposes of triangulation, expansion and development.

\section{Sample and Setting}

A non-probability sampling technique in the form of purposive sampling was used. According to Creswell (2007, p. 125), 'purposive sampling, which is also known as criterion-based sampling, is a means that the enquirer selects individuals and sites for study because they can purposefully inform an understanding of the research problem and central phenomenon in the study'. In this study it was a 'deliberate selection of information-rich sources' (Lapan, 2004, p. 242). Based on the above-mentioned arguments, the section below discusses the criteria for selecting participants.

Two-hundred and twenty-four Grade 11 Life Sciences learners at four selected high schools in Pretoria East, South Africa participated in this study. Six Grade 11 Life Sciences teachers at these schools were also involved in the study. The criteria taken into consideration to select the schools included the school environment; resources in terms of laboratory facilities and apparatus; and type of school, as these criteria may influence how learners engage with dissections (see Table 1).

It was deemed essential to select participating schools that were co-educational schools to ensure that boys and girls were exposed to similar conditions and that gender does not cause any discrepancies in the results from the different schools. It may be noted that there were no moral, philosophical, religious or ethical objections to working with animal organ dissections on the part of the teachers. They were given the opportunity to withdraw from the study should they have wished to do so. 
Table 1: Criteria taken into consideration for selecting schools

\begin{tabular}{llllc}
\hline $\begin{array}{l}\text { Pseudonyms } \\
\text { of schools }\end{array}$ & $\begin{array}{c}\text { School } \\
\text { environment }\end{array}$ & Type of school & $\begin{array}{c}\text { Laboratory facilities } \\
\text { and apparatus }\end{array}$ & $\begin{array}{c}\text { Number of } \\
\text { teachers }\end{array}$ \\
\hline A & Township & Public & Inadequate & 2 \\
B & Suburban & Public & Adequate & 2 \\
C & Suburban & Independent & Adequate & 1 \\
D & Township & Independent & Inadequate & 1 \\
\hline
\end{tabular}

\section{Instruments and Data Collection}

A pre-test was administered to the learners through their teachers during the first session, after which they performed the dissection of sheep kidneys in the second session and then wrote the same test as a posttest in the third session. The six kidney dissection lessons were video recorded. Both tests were developed and marked by the researcher. The tests were construct validated against Bloom's Taxonomy for each of five levels of questioning, namely, rote-learning questions, problem-solving questions, Learning Outcome 1 (LO1) questions that required investigation and problem-solving skills, Learning Outcome 2 (LO2) questions that required recalling of scientific knowledge, and Learning Outcome 3 (LO3) questions that required learners to relate knowledge acquired to technology, culture and society. The three learning outcomes are elaborated in the South African National Curriculum Statement of the Department of Education (2003). Participating teachers were trained before the dissection lessons regarding the use of problem-solving strategies. They were given instructions on how the problem-solving tests were to be administered in order to ensure consistency regarding the test administration.

The results were analysed quantitatively through descriptive and inferential statistics, including $t$-test, box-and-whisker plots and ANOVA. The box-and-whisker plots were used to summarise the total score data, instead of mean-and-error bar plots, because they include more detailed summary information about the distribution of the data and there are no assumptions about the symmetry or normal distribution of the data. The statistical calculations used the SAS v9.3 and BDMP release 8.1 statistical software.

The learners' questionnaire consisted of three parts:

- Section A asked for demographic details including age, gender, religion, cultural groups.

- Section $B$ consisted of closed-ended attitude statements on a Likert scale regarding dissections and problem solving.

- Section $C$ consisted of open-ended questions that allowed learners to freely express themselves.

The questionnaire was administered to all the Grade 11 Life Sciences learners in each participating school. This was meant to determine the attitude and feelings of learners towards dissections and their use in problem-solving as this would possibly influence their engagement with animal organ dissections.

The responses to the questionnaire were analysed descriptively (frequency counts and percentages). The reliability of the tests and the questionnaire using Cronbach's $\alpha$ coefficient ranged between 0.78 and 0.83 for the questionnaire and the tests, respectively. The six Grade 11 Life Sciences teachers were interviewed after the learners carried out the animal organ dissections. To ensure learners' anonymity, the same pseudonyms or code names were applied for the pre-and post-test and the questionnaire. This study was carried out without a control group to avoid disadvantaging one group of learners, which is ethically and professionally not permissible. Therefore, the findings are interpreted descriptively rather than causally. Ethical clearance was given by the University's Ethics committee.

\section{Results}

\section{Learners' Engagement with Animal Organ Dissections in the Development of Problem- solving Skills}

The issue of how learners engaged with animal organ dissections and their use in developing problemsolving skills was addressed by the data from the pre- and post-tests, lesson observations and questionnaire. 
The pre- and post-test scores were compared using a parametric matched $t$-test. The comparison for the five cognitive levels as well as the calculated total were all highly significant with $p$-values $<0.0001$, as shown in Table 2. There were no drop-outs for the tests, which resulted in 223 degrees of freedom (DF).

The box-and-whisker plots in Figure 1 show that after the learners' engagement their problemsolving scores improved. The mean was 23.41 for the pre-test and 45.64 for the post-test with the highest score being 75 marks (the maximum score) as shown in Figure 1. The median was 23 for the pre-test and 46 for the post-test, showing that the pre-test median had doubled.

Further analysis using the ANOVA compared the pre-test with the post-test learning gains on the total score and scores for each of the five levels of questioning with respect to school environment, gender and moral position. There was no statistically significant difference between the scores with respect to gender and moral position. However, with respect to school, the overall models for four of the six scores, excluding rote learning and LO3, showed significant learning gains with $p$-values of $<0.05$, model DF $=4$ and error DF $=211$ (see Table 3).

A total of $43 \%$ of the respondents indicated that they had carried out animal organ dissections in previous grades, while $57 \%$ had no experience. More than $90 \%$ of the learners who completed the questionnaires acknowledged that animal organ dissections helped them to understand the structure and functions of the kidney. According to them, it also improved their investigative skills and skills in solving real-life problems, while $93 \%$ of learners were of the opinion that animal organ dissections gave them first-hand information about the anatomy of the organ they were studying. About $90 \%$ acknowledged that it would help them to know more about their own bodies.

In terms of the learners' moral position regarding animal organ dissection, $86 \%$ of the learners responded that they morally supported animal organ dissections, because it was not cruelty since the organs were obtained from animals that were already dead and had not been killed for the sole purpose of dissection. Others of those supporting organ dissention argued that it was not murder because it was for a good cause. These results agree with earlier findings that learners tend to gain an affinity towards whatever learning methods they are exposed to. With regard to dissections, Lock and Millett (1991) found that learners' attitudes towards dissections and animal research were reinforced by participation in or exposure to these endeavours.

In this study, only $14 \%$ learners were opposed to dissection because it was against their religion; it was considered cruel to the animals; it was immoral since many animals had to die for the purpose of animal organ dissections; it was against the principles of vegetarianism; and also owing to their strong respect for animals. In surveys of UK high school learners, $38 \%$ would object to the dissections of any animal material, organs or the whole animal for various reasons including religion, being vegetarian and opposition to cruelty (Millett \& Lock, 1992), and only between 33 and $50 \%$ would carry out dissections. This shows a substantial difference between the moral standing of the UK and South African learners, possibly because the UK learners are expected to carry out whole animal dissections, unlike the animal organ dissection, which does not necessarily involve taking a life.

Table 2: Learning gains between the pre- and post-test scores

\begin{tabular}{lc}
\hline$t$-Statistic for each of the six scores & $t$ \\
\hline Total & $28.33^{\star \star \star}$ \\
Rote learning & $20.82^{\star * \star}$ \\
Problem solving & $23.95^{\star \star *}$ \\
LO1 & $21.39^{\star \star *}$ \\
LO2 & $21.35^{\star * *}$ \\
LO3 & $20.28^{\star \star *}$ \\
\hline
\end{tabular}

${ }^{* * *} p$-Values $<0.001$. All six tests had DF $=223 ; p<0.05$ was considered statistically significant. 


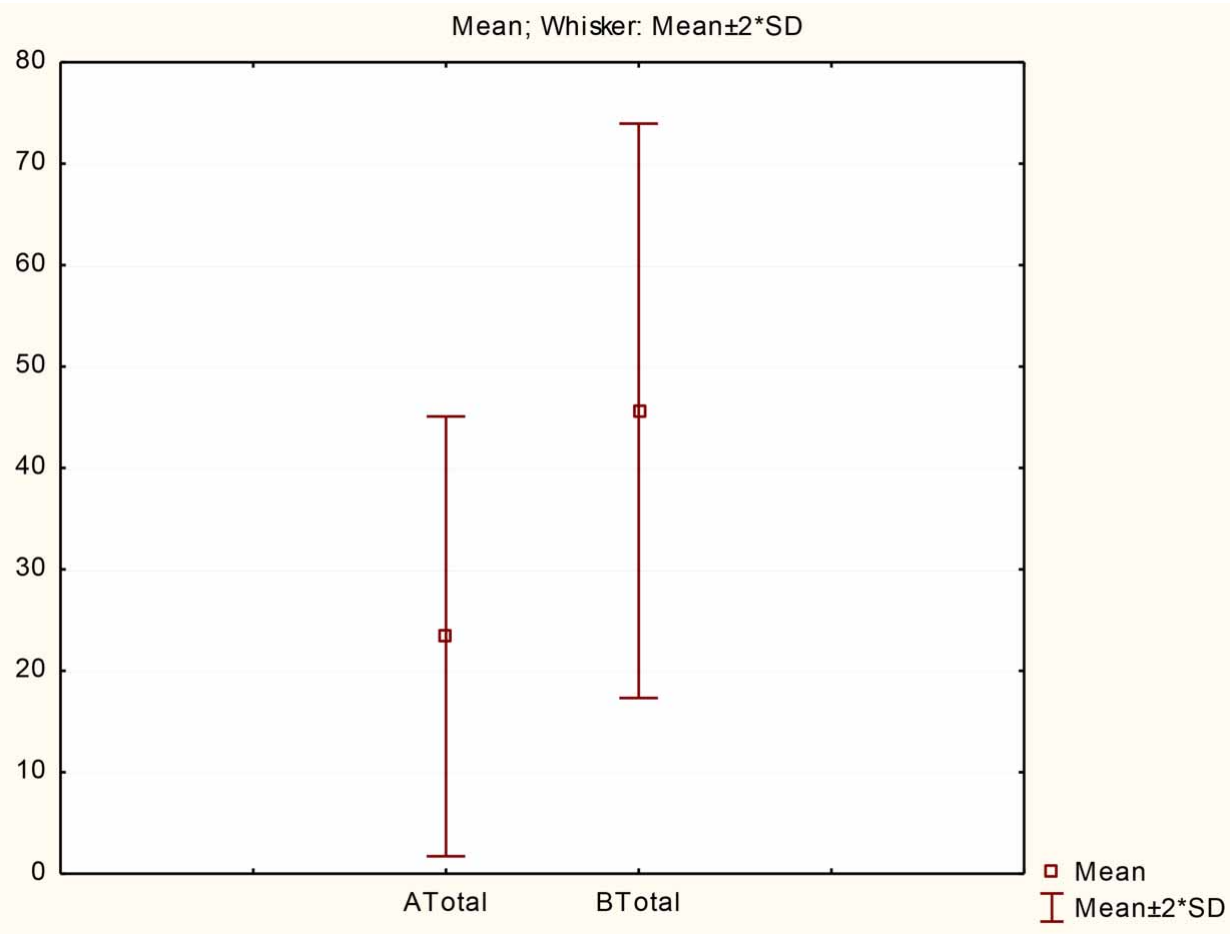

Figure 1: Mean box-and-whisker plots showing data distribution of the pre-test $(A)$ and post-test scores $(B)$

The Use of Animal Organ Dissection as a Teaching Strategy to Develop Problem-solving Skills of Learners

The issue of how teachers use animal organ dissections to develop problem-solving skills of Grade 11 learners was addressed by the data from the semi-structured interviews, lesson observations, worksheets given to learners and lesson plans. Teachers were given pseudonyms: Teacher A1 (Teacher 1 at School A), Teacher A2 (Teacher 2 at School A), Teacher B1 (Teacher 1 at School B), Teacher B2 (Teacher 2 at School B), Teacher C (Teacher at School C) and Teacher D (Teacher at School D).

Generally teachers acknowledged that animal organ dissection could be used to develop problemsolving skills by asking learners questions linking real-life excretory system aspects to what was

Table 3: ANOVA statistics for learning gains with respect to school, gender and moral position

\begin{tabular}{|c|c|c|c|c|c|c|}
\hline \multirow[b]{2}{*}{ Score } & \multicolumn{2}{|c|}{ School DF = 3} & \multicolumn{2}{|c|}{ Gender DF = 1} & \multicolumn{2}{|c|}{$\begin{array}{c}\text { Moral Position } \\
\text { DF }=1\end{array}$} \\
\hline & $F$ & $p$ & $F$ & $p$ & $F$ & $p$ \\
\hline Total & $5.34^{* * *}$ & $0.0014^{* * *}$ & 0.71 & 0.3994 & 0.64 & 0.4251 \\
\hline Rote learning & 1.49 & 0.2186 & 0.06 & 0.8078 & 0.17 & 0.6822 \\
\hline Problem solving & $6.17^{\star \star *}$ & $0.0005^{\star \star *}$ & 1.22 & 0.2707 & 0.57 & 0.4525 \\
\hline LO1 & $4.79^{\star \star \star}$ & $0.0030^{* * *}$ & 1.03 & 0.3124 & 0.04 & 0.8500 \\
\hline LO2 & $7.51^{\star \star \star}$ & $0.0001^{\star \star \star}$ & 1.29 & 0.2571 & 0.81 & 0.3697 \\
\hline LO3 & 2.34 & 0.074 & 0.19 & 0.6658 & 0.01 & 0.9199 \\
\hline
\end{tabular}

*** $p$-Values $<0.05$ considered to be significant. 
observed on the dissected organ. They also acknowledged that it required much teacher guidance to help learners focus on the parts of the organ relevant for the problem-solving tasks, as illustrated by Teacher B1:

If you use dissections to improve problem-solving skills you have to consolidate with worksheets, you have to consolidate with real life examples. It is not something like they can just have the dissection and be expected to learn from that. You actually have to help them consolidate what they have seen. I think during the dissection, if you want them to develop problem-solving skills, you have to lead them to think in that direction during the dissection. It is not something where you can just let the learners do a dissection. You have to guide them more in what problem you would want them to solve afterwards.

Teacher C, Teacher B1 and Teacher D acknowledged that using animal organ dissections in developing problem-solving skills was an improved teaching strategy that they had not considered. Now that they had done it, they planned to change their approach in the future. They had many ideas on topics for which they were going to use animal organ dissections. Teacher D suggested the following:

Well I suppose if you use like the example of diabetes and the kidney. When they dissect the kidney and you ask them to identify the nephron and then if they can link that to the diabetes where I could ask them: if there is a problem with the proximal convoluted tubule which is supposed to absorb all the glucose, where does that glucose go? Then they can follow it down through the nephron to the urethra and they can see why there's glucose in the urine and then obviously that would lead to the diagnosis of diabetes.

Teacher C supported Teacher D's idea by citing a different example of how they would use animal organ dissections to improve problem-solving skills:

I am busy now with different animal families. So you can perhaps give them as a challenge and say: I have now an example of a plant (animal) family, now you must dissect it and tell me all the different features. Does it have an endoskeleton or exoskeleton, blood system or not? They investigate all the different features. So you don't tell them beforehand look for this and this stuff. You give them the sample saying you must now discover what is in there. So that can perhaps be more challenging, they already know the diagram and they know okay this is supposed to be there and there. You give them something that they have never seen before. So perhaps that is a good idea to do it from that angle as well and they acquire investigative skill for the problem in front of them that they then solve.

During the lesson observations, it was noted that teachers A1 and A2 gave learners worksheets that required them to dissect, draw and label the diagram. These worksheets showed that the teachers had no intention of developing any other skills in the learners apart from dissecting, drawing and labelling the organ. This did not come as a surprise because one of the teachers (Teacher A2) was the same teacher that had shown a lack of understanding regarding problem-solving strategies during one of the interviews. Nevertheless, Teacher A2 acknowledged that the animal organ dissections had helped his learners to develop problem-solving skills as he argued that:

You know it [dissection] brings a lot of attention to most of the learners. Learners really want to see that which they saw in a text book, in real. They seem to enjoy it very much and I think it works well for them. I saw it in an exercise I gave them afterwards you know it proved to me really the questions that I gave before and after the dissection, you know it proved to me they were very much on the answers, after the dissection than before the dissection itself.

Teacher B1 added that:

I believe that if they can see the real life thing, they will think of it further on how something like an organ works. And they will think in a different angle, if they see how it actually looks and what implications it can have when you have a problem like a puncture in the lung, or a blockage in the urethra, that they will be able to solve their problems better and think about solutions maybe. 


\section{Discussion}

It could be argued that the learners' engagement with dissections resulted in the improvement of their problem-solving scores since there were significant differences between the pre-test and post-test means. The information on prior experience with dissections was considered relevant because it could possibly correlate with learners' attitudes towards dissections. Fančovičová, Pokop and Leskova (2013) and Holstermann et al. (2010) argued that experience in hands-on activities (like dissections) improves learners' motivation towards the hands-on aspect accompanied by a minds-on aspect, which could have an effect on their engagement with dissections. Holstermann et al. (2010) also found that learners experienced in hands-on activities like dissections showed higher interest than non-experienced learners and the type of hands-on activity showed positive correlations with attitudes towards the hands-on activity. The majority of learners (95\%) understood animal organ dissections even though only $43 \%$ had actually performed any previously. These results show that, even though $57 \%$ of the learners were engaging in hands-on animal organ dissections for the first time, they still managed to improve their performance in the tests, which had predominantly problemsolving questions.

According to the ANOVA analysis, only the school environment, unlike gender and moral position, had a significant effect on the learning gains of four levels of questioning namely total score, problem-solving, LO1 and LO2. This result did not come as a surprise because the four selected schools were from diverse environments considering the availability of laboratory facilities and apparatus. Another difference that was noticed during the lesson observations was the different teaching approaches used by the six teachers, which resulted in different levels of learner engagement with animal organ dissections in the different schools. There were no significant differences in rote-learning means and LO3 means amongst the four schools. This may be because rote learning can be achieved theoretically with a minimal level of engagement with animal organ dissections on the part of learners, irrespective of the school environments. The similar means for LO3 for the four schools may be because the learners from the four different school environments managed to apply the knowledge acquired to society at almost the same level irrespective of the different learning environments.

During the lessons observations, it was noted with great interest that many group discussions and debates were quite constructive and this may have contributed to the improvement of their problemsolving abilities. It may be asserted that the holistic learner-centred approach with minimal assistance from the teachers encouraged these learners to explore more their dissected organs and they managed to improve their problem-solving skills more than students in the other schools who were over-assisted by their teachers. Since the learners showed a positive attitude towards animal organ dissections, it meant that they would engage with the task more and in so doing acquire the necessary skills that they believed would be gained from animal organ dissections. It was also established that the moral values of learners, which can be based on religion, culture, being vegetarian, animal lovers and squeamishness, can have a great influence on their attitudes towards animal organ dissections. This was also observed by Bowd (1993) in his study on the role of dissections in the teaching of high school science.

The teachers' acknowledgement of the role of dissections in problem-solving concurs with Hofstein and Lunetta (2004) and Lock (1994) in that animal dissections do not only promote the learners' acquisition of science content, but also promote the development and use of science process skills, creative thinking, problem-solving ability and scientific method. It was noticed that the animal organ dissections lessons coupled with the problem-solving pre- and post-tests were an eye-opener to the teachers. It was evident during the interviews that the teachers had realised that it was possible to use animal organ dissections to develop problem-solving skills in their learners. The teachers cited many examples in which they could let their learners dissect and then give them problem-solving tasks that would guide them towards the development of problem-solving skills even in other topics, which was gratifying. Their opinions are in agreement with various authors (Cotic \& Zuljan, 2009; Rose \& Arline, 2009) who argue that problems given to learners must provide them with situations that are personal, meaningful and related to real-life situations. Teachers need to be well acquainted with problem-solving strategies to instil problem-solving skills in their learners. 


\section{Conclusion}

The pre- and post-test results, the lesson observation data and the questionnaire responses all indicate that learners may engage with animal organ dissections and use them to develop or improve their problem-solving skills. They can explore the organs, debate what was observed in groups challenging each other with real-life situations related to their observations, respond to problem-solving tasks given by the teacher and become less dependent on the teacher. It was considered vital to ensure that teachers are encouraged to improve their teaching strategies by using animal organ dissections in problem-solving. During the process, the learners acquire enquiry skills, including investigative skills resulting in observation, practical and problem-solving skills, which can help them to generally improve their performance in the subject and at tertiary level (McCain, 2005; Preszler et al., 2007). There is more to animal organ dissections than just cutting, drawing and labelling as a way of complying with the National Curriculum Statement of the Department of Education.

\section{Limitations of the Study}

This study was limited to a small number of Life Sciences teachers teaching in suburbs to the east of Pretoria. An implementation in different environmental settings such as rural areas may not necessarily result in similar findings since factors like culture have a stronger influence in rural areas and there is less cultural diversity.

The lesson observation data may be skewed owing to the presence of the researcher and the video recording in the classroom: in order to minimise the Hawthorne effect, the camera was stationed at the back of each classroom and filming was done as unobtrusively as possible.

\section{Educational Implications}

The study contributes directly to the body of knowledge in the possible use of animal organ dissections to develop skills that include enquiry, investigative and, most importantly, problem-solving skills.

The findings of this study should assist policy-makers, Life Sciences lecturers and Life Sciences teachers to maximise the use of animal organ dissections rather than just to use them to comply with the requirements of the National Curriculum Statement of the Department of Education.

The activities carried out with the teachers and their learners in this study could be used as a model for teacher professional development to promote the use of animal organ dissections to develop problem-solving skills in their learners.

The implementation of the problem-solving teaching strategies as used in this study may also help to increase learners' interest and achievement in Life Sciences by developing in them a positive attitude towards the subject. This is important because practical work in the sciences helps learners acquire scientific skills, as well as the scientific attitudes and values needed in solving everyday problems, especially in courses related to Life Sciences at tertiary institutions.

Finally, the results of this study may serve as a guide to further work in other areas of research such as enquiry-based learning and learner application of problem-solving skills to the learning of Life Sciences.

\section{Disclosure Statement}

No potential conflict of interest was reported by the authors.

\section{References}

Beekman, L. (2000). Problem-solving and decision-making strategies and skills. Pretoria: Van Schaik.

Bennett, J., \& Lubben, F. (2006). Context-based chemistry: The Salter's approach. International Journal of Science Education, 28(9), 999-1015. 
Bowd, A. D. (1993). Dissection as an instructional technique in high science: Choice and alternatives. Society and Animals, 1(1), 83-88.

Capps, D. K., Constas M. A., \& Crawford, B. A. (2012). A review of empirical literature on enquiry professional development: Alignment with best practices and a critique of the findings. Journal of Science Teacher Education, 23(3), 291-318.

Cotic, M., \& Zuljan, M. (2009). Problem-based instruction in mathematics and its impact on the cognitive results of the students and on affective-motivational aspects. Educational Studies, 35(3), 297-310.

Creswell, J. W. (2007). Qualitative enquiry and research design: Choosing among five approaches. Thousand Oaks, CA: Sage.

Creswell, J. W. (2009). Research design: Qualitative, quantitative, and mixed methods approaches (3rd ed.). Thousand Oaks, CA: Sage.

Creswell, J. W., \& Plano Clark, V. L. (2011). Designing and conducting mixed methods research. Thousand Oaks, CA: Sage.

Department of Education, (2003). The National Curriculum Statement. Grades 10-12 (Life Sciences). Government Printers. Retrieved February 2, 2013 from http://www.education.gov.za

De Villiers, J. J. R., \& Monk, M. (2005). The first cut is the deepest: Reflections on the state of animal dissection in biology education. Journal of Curriculum Studies, 37(5), 583-600.

Fančovičová J., Prokop, P., \& Lešková, A. (2013). Perceived disgust and personal experiences are associated with acceptance of dissections in schools. Eurasia Journal of Mathematics, Science and Technology Education, 9(3), 311-318.

Franklin, S., Peat, M., \& Lewis, A. (2002). Traditional versus computer-based dissections in enhancing learning in a tertiary setting: A student perspective. Journal of Biological Education, 36(3), 124-129.

Handelsman, J. (2004). Scientific teaching. Science, 304, 521-522.

Hart, L. A., Wood, M. W., \& Hart, B. L. (2008). Why dissection? Animal use in education. London: Greenwood.

Hofstein, A., \& Lunetta, V. N. (2004). The laboratory in science education: Foundation for the $21^{\text {st }}$ century. Science Education, 88(1), 28-54.

Holstermann, N., Grube, D., \& Bögeholz, S. (2010). Hands-on activities and their influence on students' interest. Research in Science Education, 40(5), 743-757.

Lapan, R. T. (2004). Career development across K-16 years: Bridging the present to satisfying and successful futures. Alexandria, VA: American Counselling Association.

Lock, R. (1994). Dissection as an instructional technique in high science. Society and animals, 2(1), 67-73.

Lock, R., \& Millett, K. (1991). The animals and science education project, 1990-1991. School of Education, University of Birmingham.

McCain, T. (2005). Teaching for tomorrow: Teaching content and problem-solving skills. Thousand Oaks, CA: Sage.

Millar, R. (2004). The role of practical work in the teaching and learning of science. Paper prepared for the Committee: High school Science laboratories: Role and vision, National Academy of Sciences, Washington DC. York: University of York.

Millett, K., \& Lock, R. (1992). GCSE learners' attitudes towards animal use: Some implications for biology/science teachers. Journal of Biological Education, 26(3),204-208.

Nabi, R. L. (2002). The theoretical versus the lay meaning of disgust: Implications for emotion research. Cognition and Emotion, 16, 695-703.

National Science Teachers Association (2005). Responsible use of live animals and dissection in the science classroom. Retrieved November 20, 2013 from www.nsta.org/about/positions/animals

Oakley, J. (2012). Science teachers and the dissection debate: Perspectives on animal dissection and alternatives. International Journal of Environmental and Science Education, 7(2), 254-267.

Offner, S. (1993). Importance of dissection. The American Biology Teacher, 55(3), 147-149.

Preszler, R. W., Dawe, A., Shuster, C. B., \& Shuster, M. (2007). Assessment of the effects of student response systems on student learning and attitudes over a broad range of Biology courses. CBE Life Sciences Education, 6(1), 29-41.

Randler, C., Wust-Ackermann, P., Vollmer C., \& Hummel, E. (2012). The relationship between disgust, state-anxiety and motivation during a dissection task. Learning and Individual Differences, 22, 419-424.

Roehrig, G. H., Dubinsky, J. M., MacNabb, C., Michlin, M., \& Schmitt, L. (2012). Teaching neuroscience to science teachers: Facilitating the translation of enquiry-based teaching instruction to the classroom. Life Sciences Education, 11(4), 413-424.

Rose, R., \& Arline, C. (2009). Uncovering student thinking in mathematics grades 6-12. Thousand Oaks, CA: Corwin Press. 
Smith, P. S., Banilower, E. R., McMahon, K. C., \& Weiss, I. R. (2002). The national survey of science and mathematics education: Trends from 1977 to 2000. Chapel Hill, NC: Horizon Research. Retrieved September 30, 2013 from http://2000survey.horizon-research.com/reports/trends.php

\section{Appendix: Pre- and Post-test: The Kidney}

Instruction: Study the kidney of a lamb and answer the following questions.

\section{Question 1}



1.1 Label the parts 1-17 as observed on the kidney diagram.

1.2 Relate the structure to the function of each of the parts you observed on the kidney organ you dissected.

1.3 Why is there difference in colour between the cortex and medulla?

1.4 How many pyramids can you identify in one half of the kidney?

1.5 Using the hand lens identifies and name the tiny dots in the cortex region.

1.6 (a) What is the purpose of the renal artery and (b) what results if there is blockage in this vessel? (2)

1.7 According to your observation of the kidney on the diagram and the attached photo of a human kidney, what differences did you notice between the two kidneys?

1.8 On the dissected organ identify the ureter. What results if there is blockage in this vessel?

1.9 Pretend you are a metabolic waste molecule. Illustrate on the kidney diagram the route through the excretory system within the kidney until urine is formed and sent to the bladder. Make sure you include all the important parts of the kidney that you will come into contact with as you make your journey. Then write a paragraph describing this journey which includes the nephron. 


\section{Question 2}

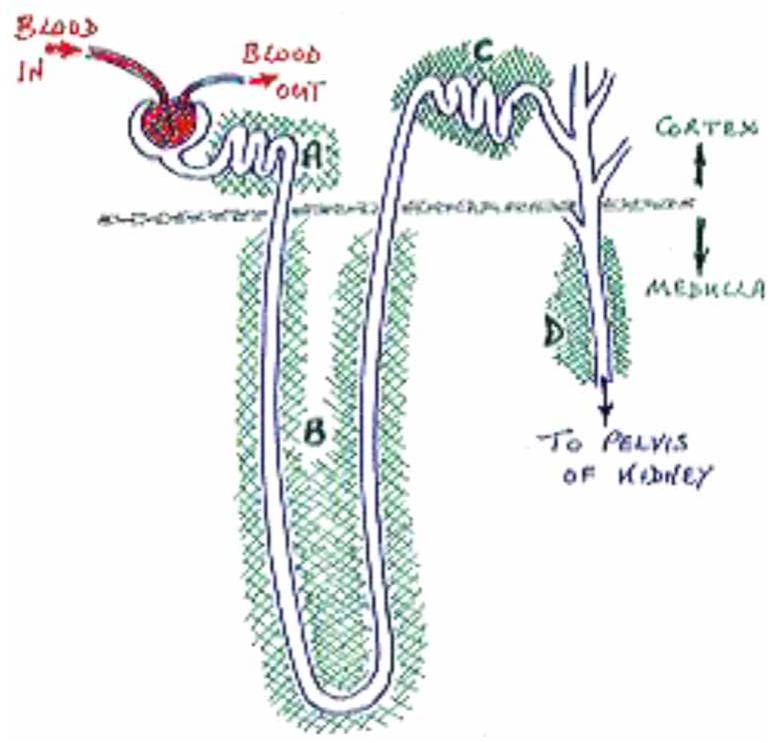

2.1 Label parts A-D and relate the structure to its function.

(8)

2.2 People with severe renal failure can be treated by dialysis, using a kidney dialysis machine, to purify the blood. (a) What are the signs of a failing kidney? (b) Which part of the kidney causes this problem?

2.3 When a person takes a drug, the drug will eventually be eliminated from the body. One of the primary mechanisms for this removal is tubular secretion. What problems in the kidneys would produce the greatest reduction in the ability of our kidneys to remove drugs?

\section{Question 3}

A group of Grade 11 Life Sciences learners carried out urinalysis (UA) which is an array of tests performed on urine, and one of the most common methods of medical diagnosis on different urine samples using urine test strips, in which the test results can be read as colour changes.

Different sets of results came out of the different urine samples and the learners had to interpret the meaning of each urine test strip and deduce what could be the renal problem that the owner of each sample had and how it could be treated. Suppose you were one of these learners and you obtained the results below, present in a form of a table what would have been (1) your interpretation of the meaning of each urine test strip, (2) the renal problem linked to the result and (3) how it could be treated. Each 
strip represents the ticked colour code of a different aspect; consider the ticked colour for samples (a), (b) and (c) when answering your questions.

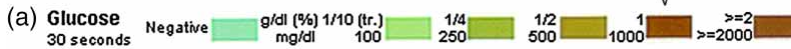

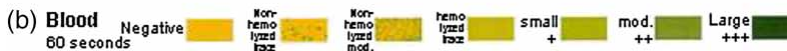

60 seconds mas.

(c) Protein Negative trace $\mathrm{mg} / \mathrm{dl}$
60 seconds
30

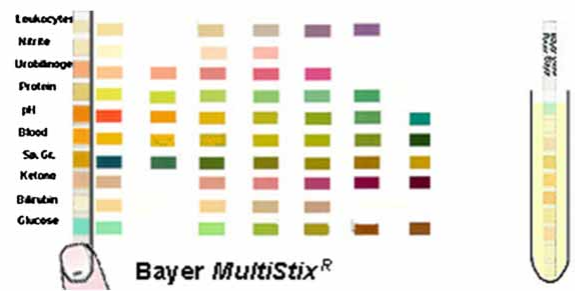

\section{Question 4}

4.1 Match the following words in column A with those terms in column B; just write down the corresponding letter in column B to the number in column A.

(6)

\section{Column A}

1. Kidney stones

2. Renal failure

3. Polycystic kidney disease

4. Glomerulonephritis

5. Haemoglobinuria or myoglobin

6. Proteinuria glomerular filtration barrier problems
Column B

(a) Inflammation in the glomeruli which disturbs the filtration process

(b) Small crystals and protein which form in the renal medulla and pass into the urine collection system

(c) Blood supply to the kidneys becomes blocked or damaged

(d) Dilations (cysts) form at the junction of the distal convoluted and collecting tubule

(e) Protein Negative trace mg/d $\begin{gathered}\text { moll } \\ 60 \text { seconds }\end{gathered}$

(f) Leukocytes $_{2 \text { minutes }}$ Negative trace small

4.2 Of the diseases mentioned in the table above, choose one that directly affects the renal medulla which you have observed on your dissected kidney and answer the following:

Background information on the disease and treatment

Economic impact

Social impact

Lifestyle change needed to improve overall health

4.3 Discuss multiple possible lifestyle modifications that could be achieved to improve the overall health of the individual suffering from a kidney disease, and help disease prevention. 